\title{
EL CAPRONATO DE 17 ALFA-HIDROXI, 19 NOR-PROGESTERONA COMO AGENTE ANTICONCEPTIVO INYECTABLE DE DEPOSITO*
}

\author{
Dr. Roberto Rodríguez-Restrepo
}

\section{Introducción}

En el presente trabajo se dan a conocer las distintas experiencias clínicas acumuladas con el empleo del Capronato de 17 Alfa-Hidroxi, 19 NorProgesterona a dosis de $200 \mathrm{mg}$. por vía intramuscular con intervalos de 8 semanas, sobre un grupo de 150 mujeres en anticoncepción voluntaria, a lo largo de un período de 16 meses, comprendido entre Julio de 1967 y Septiembre de 1968.

Con el deseo de colaborar en el desarrollo y perfeccionamiento de nuevas variantes de la anticoncepción parenteral, la Asociación Pro-Bienestar de la Familia Colombiana, Centro Piloto de Planificación Familiar, ubicado en la ciudad de Bogotá, aceptó llevar a cabo las primeras experiencias clínicas realizadas en este campo y en nuestro país con el empleo de un nuevo gestágeno de depósito, buscando determinar su eficacia anticonceptiva y su tolerancia clínica, así como hacer la evaluación en nuestro medio de la aceptación, tanto del producto en sí, como del método en general.

\section{Material y Método}

Se tomó para estudio un grupo de 150 mujeres, clínicamente sanas, sin antecedentes de enfermedad sistémica importante, madres de un hijo al menos, vida sexual activa regular, edad inferior a los 40 años, residentes en su mayoría en área urbana, sin selección de nivel económico o cultural, que se sometieron voluntariamente a un método anticonceptivo nuevo, de efectividad no comprobada, dispuestas a colaborar en los exámenes y controles exigidos.

Previa una entrevista individual y una anamnesis adecuada, cada mujer fue sometida a un examen médico general y ginecológico completo -que incluye toma de citología vaginal tumoral- cuyos datos fueron registrados en una historia clínica especialmente diseñada. Por dificultades prácticas, en ningún caso fue posible efectuar ciclo de control previo antes de iniciar el estudio.

En el $45,3 \%$ de las mujeres, la última gestación había terminado dentro de los 12 meses precedentes a su ingreso en el grupo de estudio; en las restantes, el último embarazo terminó entre los 13 y los 60 meses anteriores.

* Trabajo presentado a la Sociedad Colombiana de Obstetricia y Ginecología como requisito para ser aceptado en calidad de Miembro de Número. 
Solamente el $14 \%$ de las mujeres del grupo no había practicado anticoncepción voluntaria luego de su último embarazo; el 15\% habían recibido anovulatorios orales, el $68 \%$ habían sido usuarias del dispositivo intrauterino (DIU) y el 10\% empleaban métodos anticonceptivos diferentes.

La edad registrada en el grupo de estudio oscila entre los 17 y los 39 años, siendo la edad promedio de 27 años. El número de gestaciones oscila entre 1 y 19, con un promedio de partos de 3,8 y un promedio de abortos de 0,8 por mujer. La frecuescia de relaciones sexuales varía entre diaria y dos por mes, con promedio de 2,04 por semana y por mujer.

Tan solo el $64 \%$ de las mujeres del grupo presentaban ciclos menstruales normales antes de iniciar el estudio. El $4 \%$ presentaban alteraciones tipo polihipermenorrea; el $4 \%$ trastornos tipo oligohipomenorrea; el 7,3\% amenorrea de puerperio con o sin lactancia y el $20 \%$ irregularidades menores. No se aceptó ninguna mujer que presentase amenorrea que no fuese puerperal. Veinticinco mujeres habían abandonado el dispositivo intrauterino (DIU) por problemas de sangrado frecuente o severo.

Aunque para el estudio se prefirió no aceptar mujeres con patología, fue necesario hacer excepciones por insistencia de ellas mismas. Así, se aceptaron 9 mujeres con várices severas, 1 con várices operadas, 3 con hipertensión arterial asintomática, 6 con soplos cardíacos asintomáticos no esclarecidos y 2 con obesidad severa.

Para valorar la tolerancia del producto se estableció que la mujer relatase en forma espontánea las moles- tias presentadas desde su último control. Los datos positivos que aparecieron durante un solo control, para desaparecer luego en forma espontánea y definitiva no habrían de ser tenidos en cuenta para la valoración de los efectos secundarios. Así mismo, cuando ya había algún dato positivo al ingresar al estudio, solo se tendría en cuenta si se modificaba en forma notoria a lo largo del mismo.

El producto en estudio es el Capronato 0 Caproato de 17 Alfa-Hidroxi, 19 Nor-Progesterona, distinguido también con el nombre de Capronato de Gestonorona o con la sigla "SH-582". Se trata de un gestágeno sintético "puro" (1), sin adición de estrógenos, de acción prolongada de depósito, perteneciente al grupo de los 19 noresteroides, sin propiedades androgénicas, anabólicas ni corticoides aparentes en la experimentación animal, con actividad progestacional superior a la progesterona, libre de efectos secundarios indeseables (2).

El SH-582 es elaborado por Laboratorios Schering A.G. Berlin. Se presenta en ampolla o frasco-ampolla, a una concentración de $100 \mathrm{mg}$. por mililitro. Lleva aceite de ricino y benzoato de bencilo como vehículos (en proporción 6:5). Está destinado para administración intramuscular profunda. Su fórmula estructural aparece en el Cuadro 1.

Esquema de Administración y Posología: Para el presente estudio se estableció la dosis de $200 \mathrm{mg}$. por inyección, aplicada en la región glútea, tanto para la dosis inicial como para las de repetición.

Dosis inicial: Entre los días 3 y 6 de un ciclo precedido de menstruación espontánea o inducida, en mujeres con menstruaciones presentes 0 entre los días 30 y 40 del puerperio, 


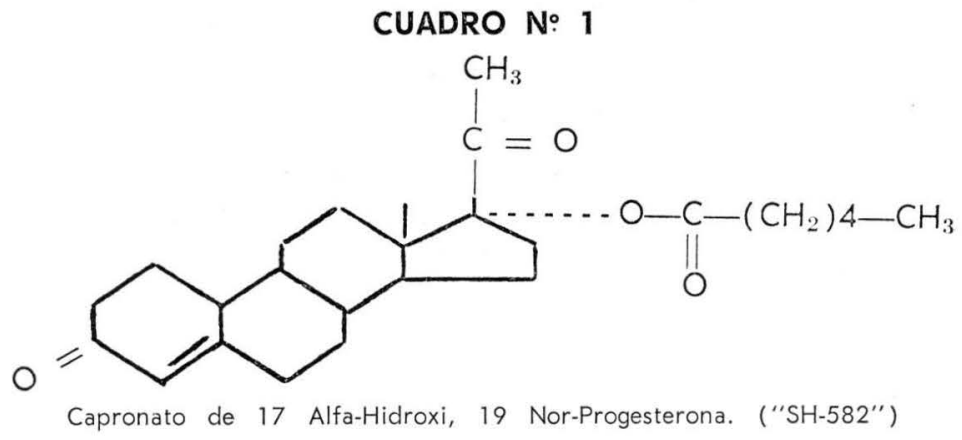

sin inducir menstruación en mujeres puérperas, con o sin lactancia.

Dosis de repetición: Cada 8 semanas a partir de la inyección precedente, no teniendo en cuenta entonces la fecha de la última menstruación. En caso de la omisión de una dosis de repetición, habría de esperarse la siguiente menstruación espontánea para reiniciar el día 3 del ciclo siguiente.

Toda inyección habría de ser aplicada durante una visita de control, no permitiendo que la ampolla fuera entregada a la mujer para que un tercero la aplicase en fechas posteriores o fuera de la Clínica.

\section{Resultados}

Se revisan las historias clínicas de 150 mujeres, sometidas a la acción anticonceptiva del $\mathrm{SH}-582$, durante períodos variables que oscilan entre uno y trece meses.

El $12 \%$ de estas mujeres recibieron el gestágeno durante un año o más en forma continua; el $34 \%$ lo recibieron entre 6 y 12 meses; el $44 \%$ entre 2 y 6 meses y el $10 \%$ durante 8 semanas o menos.

En este grupo de mujeres se totalizan 1.032 meses de control, durante los 16 meses del estudio. El número total de controles efectuados es de
964, con un promedio de 0,93 control por mes por mujer. El número de inyecciones aplicadas asciende a 509, con variación de 1 a 7 inyecciones por mujer.

Se analizan:

Abandono.

Embarazo.

Alteraciones sobre el ciclo menstrual.

Efectos colaterales.

\section{Abandono}

De las 150 mujeres iniciales, 120 continúan "activas" al finalizar el estudio en Septiembre de 1968.

La Tasa de Abandono es de un $20 \%$.

Las diferentes causas de abandono aparecen expuestas en el Cuadro 2.

\section{Embarazo}

De las 120 mujeres "activas", 16 presentaron embarazo comprobado atribuíble a falla del método.

La Tasa de Embarazo, según el índice de Pearl es de 18,0 por cien años mujer.

En el Cuadro 3 se exponen los embarazos ocurridos, incluyendo, a título de información, aquellos debidos 


\section{CUADRO № 2}

(ABANDONO)

$\begin{array}{ll}\text { Causa desconocida: } & 10 \text { mujeres. } \\ \text { Cambio de ciudad: } & 3 \text { mujeres. } \\ & \\ \text { Indicación médica: } 4 & \text { 1. Polimenorrea } \\ & \text { 1. Polihipermenorrea } \\ & \text { 1. Sangrados prolongados } \\ & \text { 1. Intolerancia local } \\ & \text { 2. Orden del esposo } \\ & \text { 3. Alteraciones menstruales } \\ & \text { 1. Aumento molestias gástricas } \\ & \text { 1. Proceso anexial recidivante } \\ & \text { 1. Afección renal aguda } \\ & \text { 4. Después de presentar retrasos sugestivos de embarazo } \\ & \text { 1. Pérdida de peso (1,5 kg.) }\end{array}$

* 3 mujeres no regresaron después de la la. dosis.

a omisión de dosis siguientes y a abandono del método.

Todos los embarazos se presentaron pasadas las primeras 4 semanas desde la última dosis, puesto que todas estas mujeres tuvieron menstruación entre las 3 y las 6 semanas después de esta última.

\section{CUADRO № 3}

\section{(EMBARAZO)}

\footnotetext{
Después de la la. dosis

Después de la 2a. dosis

Después de la $3 a$. dosis

Después de la $4 a$. dosis

Por omisión 2a. dosis

Por omisión 3a. dosis

Por omisión 5a. dosis
}

Después de abandono voluntario del método (a los 4 meses)

Una de las mujeres concibió luego de presentar reacción local aguda en la región glútea, después de recibir la primera inyección. Esta mujer abortó e insistió en continuar con el método, volviendo a presentar reacción local menos severa en el sitio de la aplicación de la siguiente dosis, razón por la cual se le aconsejó cambio de método.
En ninguno de los embarazos ocurridos se ha comprobado evolución o término. De los 20 embarazos registrados, 9 han terminado en aborto durante el primer trimestre de gestación, habiendo comprobado que solamente uno de ellos fuera provocado. Siete de las mujeres que han abortado han regresado al programa de inyección y en ninguna se presentó un segundo embarazo. Seis embarazos cursan actualmente el primer trimestre de gestación. De los 5 embarazos restantes registrados se desconoce su evolución, no habiendo sido posible lograr su seguimiento debido a las falsas direcciones suministradas.

\section{Alteraciones sobre el ciclo menstrual}

La perturbación principal observada bajo efecto del $\mathrm{SH}-582$ recae sobre los ciclos menstruales, alterándolos en frecuencia, duración y cantidad, en un elevado número de ciclos. Sinembargo estas alteraciones no son $\tan$ frecuentes ni tan significativas como las observadas bajo acción de 
otros gestágenos inyectables de depósito.* (3).

Con el ánimo de simplificar la exposición de las alteraciones encontradas durante el estudio, se exponen en el Cuadro 4, en forma de porcentajes, los ciclos de las 18 mujeres que han alcanzado un año de observación, considerando que es una muestra representativa de las alteraciones encontradas.
Se hace la aclaración de que los porcentajes del Cuadro 4 están basados en los 182 ciclos que se presentaron durante los 222 meses de control revisados en las 18 mujeres que sobrepasaron el año de estudio. Hay pues una disminución del $18 \%$ en el número de ciclos reales en relación con los que teóricamente deberían haberse presentado. Esto es debido a que los ciclos bajo la acción del $\mathrm{SH}$ 582 tienden a hacerse "largos" O a alternar con "amenorreas cortas".

\section{CUADRO Nㄴ 4}

\section{(CICLOS MENSTRUALES)}

\begin{tabular}{|c|c|c|c|}
\hline \multicolumn{4}{|l|}{ Frecuencia: } \\
\hline & Ciclos "normales" & (22-35 días) & $46,3 \%$ \\
\hline & Ciclos "cortos" & $(-21$ días $)$ & $17,7 \%$ \\
\hline & Ciclos "largos" & (36-60 días) & $31,6 \%$ \\
\hline & Amenorrea "corta" & (60-90 días) & $4,4 \%$ \\
\hline & Amenorrea "larga" & (+ 90 días $)$ & \\
\hline \multicolumn{4}{|l|}{ Duración del sangrado: } \\
\hline & "Normal" & ( $3-7$ días $)$ & $80,6 \%$ \\
\hline & "Corta" & (- 3 días) & $8,9 \%$ \\
\hline & "Prolongada" & $(+8$ días $)$ & $10,5 \%$ \\
\hline \multicolumn{4}{|l|}{ Cantidad del sangrado: } \\
\hline & "Normal" & & $69,3 \%$ \\
\hline & "Escaso" & & $21,2 \%$ \\
\hline & "Abundante" & & $9,5 \%$ \\
\hline \multicolumn{4}{|l|}{ Clase de sangrado: } \\
\hline & Espontáneo & & $96,0 \%$ \\
\hline & Inducido** & & $4,0 \%$ \\
\hline Manchado intermenstrual ("spoting") & & & $5,0 \%$ \\
\hline
\end{tabular}

Las 11 mujeres que recibieron la primera dosis entre los días 30 y 40 del puerperio, sin inducción de menstruación, presentaron sangrado entre los 10 y los 15 días post-inyección, independientemente de que estuviesen 0 no en lactancia, para continuar menstruado posteriormente.

La amenorrea no es frecuente bajo acción del producto y por lo general es de duración corta, como se ha podido comprobar en aquellas que han evolucionado espontáneamente sin inducir sangrado. Ninguna amenorrea ha alcanzado los 90 días. En todos los "retrasos" o "amenorreas cortas" en que ha sido preciso inducir el sangrado, empleando sistemáticamente un compuesto gestágeno-estrógeno por vía oral**, se ha obtenido respuesta dentro de los siguientes 8 días. Se observó que los sangrados prolongados, abundantes 0 intermenstruales son más frecuentes durante los primeros meses del estudio, habiendo tendencia a su desaparición espontá-

\footnotetext{
* Experiencias personales del autor con Enantato de NorEtisterona ("SH-393").

** Duogynon Oral.
} 
nea en el curso de los meses siguientes.

Se han registrado sangrados prolongados hasta de 40 días, por lo general de muy escasa cantidad, de sangre "negra" en ocasiones, sin otra molestia que la incomodidad manifestada por la mujer. Cuando ha sido posible tomar biopsia de endometrio, por lo general se ha obtenido tejido suficiente para su estudio. Los endometrios encontrados en dichas biopsias han sido uniformemente de tipo proliferativo.

Dos sangrados abundantes han requerido legrado uterino para cohibir la hemorragia. En los dos se comprobó la existencia de endometrio de tipo proliferativo. Las dos mujeres han continuado con la inyección y en ninguna de ellas se han repetido dichos sangrados.

A tres mujeres se aconsejó cambio de método por sangrados frecuentes, abundantes o prolongados. Estas mujeres empezaban a manifestar síntomas de anemia.

Con el fin de controlar los sangra- dos abundantes, hemos recurrido tentativamente a oxitócicos de tipo ergonovina, indicándola por vía oral a las dosis usuales, durante 3 a 5 días, sin obtener prácticamente ningún resultado favorable.

Así mismo, para controlar los sangrados prolongados, hemos utilizado Etinil-Estradiol* por vía oral, en dosis de 0,06 a $0,1 \mathrm{mg}$. día, durante 3 a 8 días, obteniendo resultados variables, pero generalmente insatisfactorios.

Hemos observado igualmente lo que llamamos "retrasos compensatorios", que son retrasos variables en la aparición de la siguiente menstruación y se presentan con frecuencia después de haberse registrado un sangrado previo de tipo abundante y/o prolongado.

\section{Efectos colaterales}

Aparte de las alteraciones producidas sobre los ciclos menstruales, que han merecido un capítulo, no se han encontrado alteraciones de mayor significación bajo efectos del SH-582.

\section{CUADRO N: 5}

\section{(EFECTOS COLATERALES)}

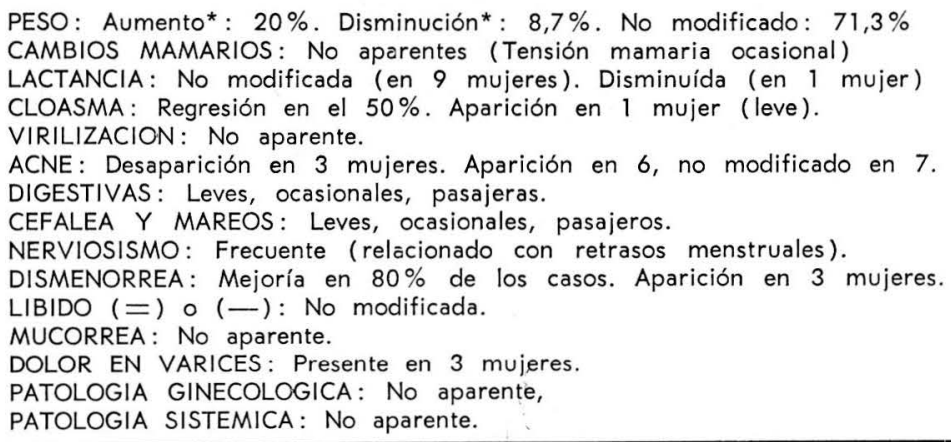

\footnotetext{
* Progynon $\mathrm{C}$.
} 
En el Cuadro 5 se exponen los signos y síntomas considerados, con breves comentarios al respecto.

Con respecto al Cuadro 5, se anota que no todas las puérperas registraron disminución de peso.

Entre mujeres se presentó acné facial leve, de tipo piógeno. Llama la atención la aparición, en 3 mujeres, de un brote fino localizado en la frente, con prominencia de los poros y congestión de los mismos, que se asemeja a la descrita en la sudamina (4), sin infección piógena sobreagregada. Esta lesión no ha desaparecido con tratamientos locales y en ningún caso ha sido tan severa como para que la mujer desee abandonar el método.

El producto ha sido localmente bien tolerado y tan solo en otra mujer (distinta de la del embarazo postreacción aguda local) se presentó dolor y reacción leve después de dos inyecciones.

Una de las mujeres que acusó dolor en los trayectos varicosos y por cuya causa llegó a aconsejársele cambio de método, cursaba simultáneamente un embarazo reciente debido a falla del método.

En los 3 casos de hipertensión arterial se observó un descenso moderado de las cifras tensionales durante todos los controles.

En ninguna de las mujeres con soplos cardíacos asintomáticos hubo evidencia de patología cardiopulmonar.

En ningún caso se ha observado patología ocular.

\section{Estudios complementarios practicados}

Aunque el propósito básico del actual estudio es realizar la evaluación clínica del producto en mención, fué posible efectuar algunas pruebas y exámenes con el interés de conocer algo referente a los posibles cambios sobre los órganos efectores por acción del gestágeno.

Así, se tomaron 37 biopsias de endometrio, en diferentes épocas del ciclo y a lo largo del estudio, de cuya revisión sobresalen las observaciones siguientes:

1. No observamos transformación secretora temprana del endometrio, por acción exógena del gestágeno. (En 4 biopsias tomadas entre los días 13 y 15 del primer ciclo, solo se encontraron endometrios tipo proliferativo).

2. No observamos tampoco imágenes secretoras en las tomas efectuadas entre los días 23 y 26 del primer ciclo. (De 12 biopsias, 10 mostraron endometrio proliferativo y 2 mostraron endometrios irregulares poco activos de tipo "atrófico".

3. De las 7 biopsias logradas al iniciarse la primera o segunda menstruación post-inyección, 4 mostraron imágenes proliferativas y tan solo 3 mostraron imágenes secretoras, no típicas.

4. Se observa actividad endometrial aceptable a lo largo del estudio. (En 8 biopsias tomadas entre los 6 y los 9 meses de recibir el gestágeno, tan solo 1 muestra "atrofia" endometrial).

Los extendidos vaginales obtenidos para apreciación funcional del epitelio vaginal, muestran en general una disminución en los índices de cariopicnosis y de eosinofilia, con aumento de las células de la capa intermedia. Durante la supuesta fase ovulatoria del primer ciclo post-inyección se observa un moderado efecto estro- 
génico (compatible con un día 8-10 de un ciclo teórico de 28 días). En las láminas tomadas entre los días 23 y 25 del mismo ciclo, de las mismas mujeres, se observan imágenes similares a las anteriores, sin las características del efecto progestacional.

Simultáneamente con las tomas de citología funcional se observaron las características del moco endocervical, encontrando en la supuesta fase ovulatoria, disminución en filancia y disminución en la arborización en hoja de helecho al examen microscópico. En la segunda fase del mismo ciclo se encontraron mocos con características francamente estrogénicas macro y microscópicamente, así como mocos atípicos difíciles de interpretar.

En un grupo reducido de mujeres se logró practicar una prueba de Sims-Huhner, modificada (con toma y examen del moco endocervical entre las 14 y las 20 horas post-coito). Dicho examen fue llevado a cabo en la supuesta fase ovulatoria del primer ciclo entre los 9 y los 12 días después de administrar la primera inyección. De 9 pruebas practicadas, 2 mostraron ausencia de espermatozoides y 1 necrozoospermia total; en las 6 restantes se encontraron formas móviles aunque en porcentajes reducidos, que variaron entre 5 y $15 \%$, consideradas como motilidad excelente en 2 , buena en 1 , regular en 2 y pobre en 1.

\section{Comentarios}

Por los estudios complementarios practicados y por los embarazos ocurridos a lo largo del estudio, no se puede pensar en sumación de efectos por repetición de dosis, al menos durante las primeras 4 inyecciones. El embarazo ha sido posible durante los intervalos de estas $4 \sin$ que se haya registrado ninguna omisión. Tampoco se puede pensar en una hostilidad franca del moco endocervical a los espermatozoides durante el primer ciclo bajo acción del gestágeno. La ausencia casi total de transformación secretora del endometrio y el bajo nivel estrogénico observado en el epitelio vaginal y su falta de relación con la fecha del ciclo teórico, hacen pensar en la posibilidad de que el gestágeno exógeno modifique en alguna forma el mecanismo o el metabolismo hormonal endógeno, produciendo un estado puramente estrogénico sobre los órganos efectores, que impediría durante un corto tiempo el embarazo y/o su nidación. El equilibrio hormonal se restablecería en algunas mujeres alrededor de las cuatro semanas post-inyección y en otras más tardíamente, para permitir y dar explicación a los embarazos descritos.

Me parece de importancia, después de haber desarrollado el presente estudio, hacer énfasis de manera reiterada en la motivación individual y permanente requerida para que un programa de esta naturaleza pueda tener éxito. Hay que tener en cuenta que la característica común de todos los preparados inyectables hormonales de depósito actualmente en uso con fines anticonceptivos, es la alteración que producen sobre los ciclos menstruales, en mayor o menor grado según el producto utilizado (5), (6), (7). Puede afirmarse que el único parámetro de que dispone la mujer con vida sexual activa para suponer el hecho de no haber quedado embarazada durante el mes precedente, es la aparición del sangrado menstrual. Sin la aparición de una menstruación esperada, en la mujer se crea la duda de un posible embarazo aún cuando esté utilizando el mejor de los métodos anticonceptivos. Empieza a presentar nerviosismo que 
puede llegar hasta la angustia, desaveniencias familiares, agresividad contra el médico que controla el método empleado, así como síntomas neurovegetativos de toda clase. La inducción hormonal de la menstruación ha sido en muchas ocasiones la única arma para mantener a la mujer bajo control, devolviéndole su tranquilidad, obteniendo la desaparición de muchos síntomas y molestias, evitándole recurrir a la automedicación y aún a medidas abortivas.

Así mismo, en un programa de esta índole, que requiere controles periódicos, la mujer debe recibir un tratamiento integral por parte del médico encargado, dentro de las posibilidades del centro a donde asiste, no limitándose a recibir atención con fines puramente anticoncepcionales. Gran proporción de las mujeres que he entrevistado y que conozco a través de este estudio, hacen verdaderos esfuerzos para acudir a sus controles y muchas de ellas carecen de medios para proporcionarse atención médica adicional.

Por último, quiero agradecer al personal directivo, administrativo, médico y paramédico de la Asociación ProBienestar de la Familia Colombiana, así como al Departamento Médico de Química Schering Colombiana S. A., la colaboración prestada durante y para la realización de este estudio.

\section{Conclusiones}

El Capronato de 17 Alfa-Hidroxi, 19 Nor-Progesterona ("SH-582"), empleado a la dosis de $200 \mathrm{mg}$. por in- yección intramuscular, con intervalos de 8 semanas:

1. No es un agente anticonceptivo que ofrezca alta seguridad.

2. Es de acción anticonceptiva segura durante un período aproximado de 4 semanas.

3. Es de efecto favorable sobre la dismenorrea, presentándose su disminución o desaparición en el $80 \%$ de los casos.

4. No modifica significativamente la lactancia, durante su empleo continuo de un año.

5. Carece prácticamente de efectos secundarios indeseables.

6. Clínicamente, su mayor alteración recae sobre los ciclos menstruales.

7. Ha sido un método altamente bien aceptado en el grupo de mujeres estudiadas.

\section{BIBLIOGRAFIA}

1 HALLER, J. Ovulostasis Hormonal. pp. 5255. 1966.

2 SCHERING A.G. BERLIN. "Product Information SH 582". Sept. 1965.

3 TYLER, E. T. "Proc. VIII Internat. Conf. IPPF". pp. 260-62. 1967.

4 TOBIAS, N. Manual de Dermatología. pp. 513. 1945.

5 TAYMOR, M. L., PLANCK, S. \& YAHIA, C. Fertil \& Steril. 15. 653. 1965.

6 ZAÑARTU, J., NAVARRO, C. "Proc. VI Pan Am. Congress Endoc". pp. 150-56. 1965.

7 LARRAÑAGA, A., KESSERU, E. Proc. V Congreso Lat. Am. Obst. \& Ginec. 1966. 